\title{
Analysis of total signal decay and capacity of information data in wireless atmospheric communication links. Part 2
}

\author{
Juwiler I. a, PhD, Senior Lecturer, orcid.org/0000-0002-0669-7828 \\ Bronfman I. a, Assistant, orcid.org/0000-0001-6195-069X \\ Blaunstein N. ${ }^{\text {b }}$ Dr. Sc., Phys.-Math., Professor, orcid.org/0000-0003-2945-9379, \\ nathan.blaunstein@hotmail.com \\ aElectrical and Electronics Engineering Department, Shamoon College of Engineering, Jabotinsky St., 84, \\ Ashdod, 77245, Israel

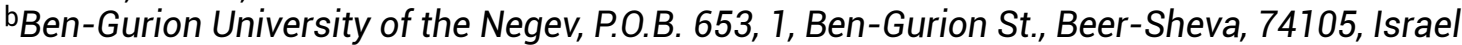

\begin{abstract}
Introduction: Analysis of total signal decay is based on prognosis of the total path loss occurring in the atmospheric communication links, accounting for effects of gaseous structures attenuation and scattering, hydrometeors (rain, snow and clouds) absorption and attenuation, and turbulent structures fast fading on radio and optical signals passing atmospheric channels with fading. Purpose: To perform a novel methodology of definition and estimation of effects of decay, absorption, scattering, and fading of radio and optical signals propagating in atmospheric channels in various meteorological conditions. Results: Was analyzed the impact of gaseous structures, hydrometeors and turbulent structures in total path loss for link budget design and in degradation of data stream parameters, such as capacity, spectral efficiency and bit-error-rate, which lead in loss of information data signals passing such kinds of channels with fast fading and decrease of quality of service. An optimal algorithm was found of the total path loss prediction for various meteorological situations occurring in the real atmosphere at different heights and for various frequencies of radiated signals. A method was proposed of how to evaluate the data stream parameters, capacity, spectral efficiency and bit-error-rate, accounting for the effects of atmospheric turbulence impact on fast fading, which corrupts information passing such kinds of channels. All practical tests were illustrated by the use of the MATLAB utility. A new methodology was proposed on how to evaluate and estimate the capacity, the spectral efficiency, and the loss in energy and in the information data stream for different scenarios of radio and optical signals propagation via atmospheric channels with fading caused by different meteorological conditions. Practical relevance: The results obtained allow to achieve better accuracy of prognosis and increase quality of service in atmospheric communication channels.
\end{abstract}

Keywords - absorption, attenuation, bit-error rate, capacity, clouds, fast fading, gaseous structures, hydrometeors, rain, Ricean factor $K$, snow, scintillation index, spectral efficiency, turbulence.

For citation: Juwiler I., Bronfman I., Blaunstein N. Analysis of total signal decay and capacity of information data in wireless atmospheric communication links. Part 2. Informatsionno-upravliaiushchie sistemy [Information and Control Systems], 2020, no. 1, pp. 54-62. doi:10.31799/1684-8853-2020-1-54-62

Ending.

Start in Informatsionno-upravliaiushchie sistemy [Information and Control Systems], 2019, no. 6, pp. 43-53, doi:10.31799/1684-8853-2019-6-43-53

\section{Total path loss in atmospheric communication links}

Path loss in free space

The path loss defined as the ratio or logarithmic difference between the amplitudes, $P\left(r_{j}\right)$, or intensity (power), $P\left(r_{j}\right)$, at any two different points $r_{1}$ and $r_{2}$, the transmitter point and receiver point accordingly. It is usually expressed in decibels [dB] and denoted by $L$ [3]:

$$
L=10 \log \left(\frac{P\left(r_{2}\right)}{P\left(r_{1}\right)}\right)=10 \log \frac{A^{2}\left(r_{2}\right)}{A^{2}\left(r_{1}\right)} .
$$

For non-isotropic sources (antenna, laser) placed in the free space the path loss is given by

$$
L=10 \log \frac{P_{T}}{P_{R}}=10 \log \left[\left(\frac{4 \pi r}{\lambda}\right)^{2} / G_{T} G_{R}\right],
$$

where $P_{T}$ and $P_{R}$ are the power, $\mathrm{W}$, of the transmitter and the receiver which have directivity gain of $G_{T}$, $G_{R}$, respectively; $r$ is distance, $\mathrm{km}$. From (46) yields

$$
L=L_{0}+10 \log \left[\frac{1}{G_{T} G_{R}}\right]
$$

Here $L_{0}$ is the path loss of isotropic point source $\left(G_{T}=G_{R}=1\right)$ in free space and can be presented in decibels as

$$
\begin{aligned}
L_{0} & =10 \log \left(\frac{4 \pi f r}{c}\right)^{2}=20 \log \left(\frac{4 \pi f r}{c}\right)= \\
& =32.44+20 \log (r)+20 \log (f),
\end{aligned}
$$

where $f$ - frequency, MHz.

All the above formulas are related to the wellknown Friis formula discussed in [3, 4]. As of now we can obtain the path loss between two directive 
antennas (receiver and transmitter) located in free space (FS) as

$$
\begin{gathered}
L_{F S}=32.44+20 \log (r)+ \\
+20 \log (f)-10 \log \left(G_{T}\right)-10 \log \left(G_{R}\right) .
\end{gathered}
$$

\section{Fading effects estimation}

Usually, fading effects can be estimated by use of $K$-parameter of fading as an additional contribution to LOS, accounting the multipath effect on signal components:

$$
K=\frac{\text { LOS-component power }}{\text { Multipath-component power }} .
$$

The most comprehensive distribution to describe the fast fading effects is the Ricean distribution because it includes both line-of-sight (LOS) together with scattering and diffraction with non-line-ofsight (NLOS) and is defined as [4]

$$
\begin{gathered}
P D F(r)=\frac{r}{\sigma^{2}} \exp \left[-\frac{\left(r^{2}+A^{2}\right)}{2 \sigma^{2}}\right] I_{0}\left(\frac{A r}{\sigma^{2}}\right), \\
A>0, r \geq 0,
\end{gathered}
$$

where $A$ is the peak strength; $\sigma$ is standard deviation of the signal envelope; $I_{0}$ is the modified Bessel function of the first kind and zero order. Using (50) and (51), the distribution function in decibels can be derived. The signal deviation from the mean on a dBscale can be calculated using the following equation:

$$
y=20 \log (r / A)
$$

The resulting probability density function (PDF) of $y$ is given by

$$
\begin{gathered}
P D F(y)=2 K \ln 10 \frac{10^{2 y / 20}}{20} \times \\
\times e^{\left(-2 K\left(10^{2 y / 20}+1\right)\right)} I_{0}\left(2 K \cdot 10^{y / 10}\right) .
\end{gathered}
$$

Figure 11 shows the $P D F(y)$ for various values of $K$ for various fluctuations. When $K \rightarrow \infty$ the Rician distribution fading approaches a Gaussian one, producing "Dirac-delta function", while for $K \rightarrow 0$, the worst scenario of the fading channel is described by Rayleigh PDF.

For our computations, the smallest $K$ that had been calculated was approximately 4 and the largest was approximately 121 . The fast fading loss was calculated from Fig. 11 by comparing the signal strength $[\mathrm{dB}]$ of the maximum value of the PDF:

$$
y[\mathrm{~dB}]=10 \log \left(\frac{L_{F F}}{r m s}\right)[\mathrm{dB}],
$$

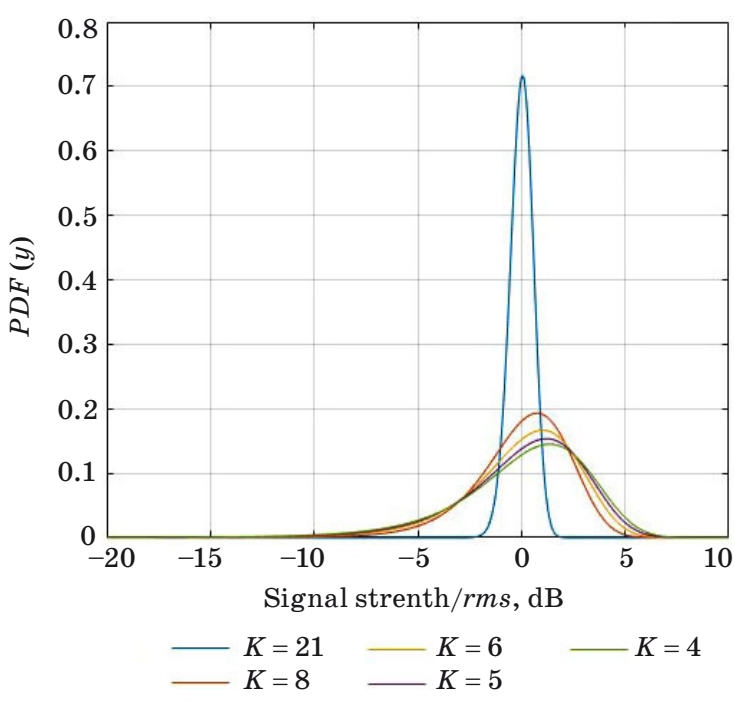

- Fig. 11. PDF distribution versus signal to $r m s$ [dB] for values of Ricean parameter $K$ of fading

while the $r m s$ is equal $\sqrt{2 \sigma}$, so the fast fading loss $\left(L_{F F}\right)$ is equal to

$$
L_{F F}=y+10 \log (r m s)[\mathrm{dB}] .
$$

\section{Link budget design}

The total path loss is difficult to be measured directly, since various losses and gains in the radio system also need to be considered. These are best accounted for by constructing a link budget, which is usually the first step in the analysis of a wireless communication system [9]. The link budget is the calculation of signal power, noise powers and/or signal-to-noise ratios (SNR) for a complete communication system or links.

Link budget is simply the maximum acceptable path loss and is usually split into two components, one of which is given by the distance-dependent path loss model plus a fade margin, which is included to allow the system some resilience against the practical effects of signal fading beyond the value predicted by the model:

$$
\begin{aligned}
& \text { Maximum acceptable propagation loss = } \\
& =\text { Predicted loss }+ \text { Fade margin }[\mathrm{dB}] .
\end{aligned}
$$

For the tropospheric link the total link budget is the sum of all the predicted losses such as the transmission line loss and the attenuation from the hydrometeors such as rain, clouds and fog. Included in this are the factors of fast fading caused by atmospheric turbulence and multipath phenomena caused by diffuse scattering. Finally, subtracting from this the gains of the antennas $G_{1}$ and $G_{2}$, the link budget can be given as 


\begin{tabular}{|c|c|c|c|c|c|c|c|c|c|c|c|}
\hline & 의 & 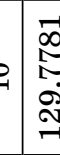 & 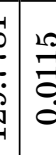 & 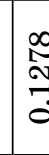 & 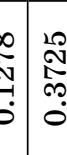 & & $\begin{array}{l}\infty \\
\stackrel{0}{0} \\
\dot{0}\end{array}$ & 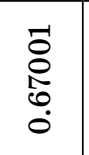 & 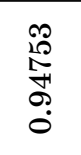 & 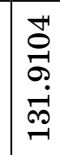 \\
\hline & & $\sim$ & 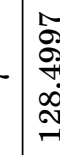 & $\begin{array}{l}\vdots \\
\vdots \\
\vdots \\
\vdots\end{array}$ & 告 & 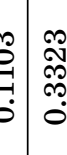 & & 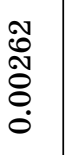 & 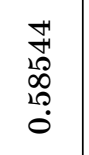 & 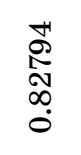 & 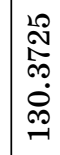 \\
\hline & & م1 & . & $\begin{array}{l}\infty \\
\infty \\
0 \\
0\end{array}$ & 흥 & 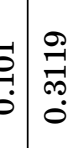 & & $\begin{array}{l}\text { Fै } \\
\text { Jै } \\
\stackrel{0}{0}\end{array}$ & 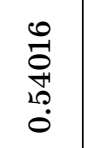 & $\begin{array}{l}\stackrel{8}{8} \\
\stackrel{0}{0} \\
0\end{array}$ & 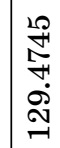 \\
\hline & & - & 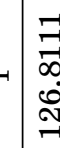 & 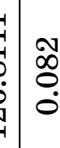 & $\mid \begin{array}{l}\infty \\
\stackrel{0}{0} \\
0 \\
0\end{array}$ & 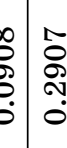 & & 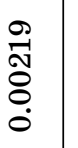 & $\begin{array}{l}\infty \\
\infty \\
0 \\
\infty \\
\stackrel{0}{0} \\
0\end{array}$ & $\begin{array}{l}\stackrel{0}{\stackrel{0}{0}} \\
\text { Oे } \\
\stackrel{0}{0}\end{array}$ & 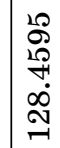 \\
\hline & ₹ & $\stackrel{?}{-}$ & 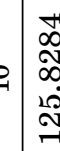 & 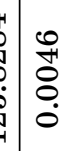 & $\begin{array}{l}8 \\
0 \\
0\end{array}$ & 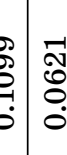 & & $\begin{array}{l}\text { ڤै } \\
\stackrel{8}{8} \\
\stackrel{0}{0}\end{array}$ & 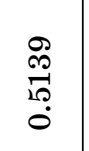 & 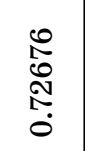 & 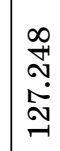 \\
\hline 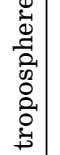 & 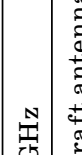 & | & - & $\begin{array}{l}10 \\
10 \\
8 \\
0 \\
0\end{array}$ & $\begin{array}{l}8 \\
8 \\
0 \\
0\end{array}$ & 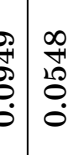 & & 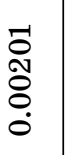 & $\begin{array}{l}\stackrel{+}{8} \\
\stackrel{+}{+} \\
\stackrel{+}{0} \\
0\end{array}$ & 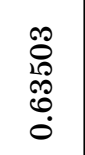 & $\begin{array}{l}10 \\
2 \\
2 \\
20 \\
2\end{array}$ \\
\hline 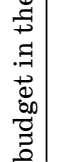 & 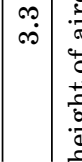 & 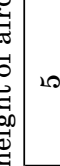 & : & $\begin{array}{l}0 \\
\vdots \\
\vdots \\
\vdots \\
0\end{array}$ & $\begin{array}{l}0 \\
\dot{0} \\
\infty \\
0 \\
0\end{array}$ & 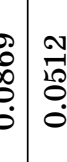 & & $\begin{array}{l}20 \\
0 \\
\stackrel{0}{0} \\
\stackrel{0}{0} \\
0\end{array}$ & $\begin{array}{l}\overrightarrow{9} \\
\stackrel{F}{\sharp} \\
\stackrel{+}{0}\end{array}$ & $\begin{array}{l}\text { Oे } \\
10 \\
\infty \\
10 \\
0 \\
0\end{array}$ & 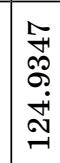 \\
\hline 部 & $\ddagger$ & 竧 & 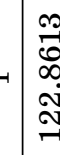 & 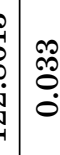 & $\begin{array}{l}\infty \\
\stackrel{\infty}{0} \\
0\end{array}$ & 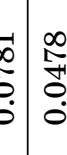 & & $\begin{array}{l}0 \\
0 \\
0 \\
0 \\
0 \\
0 \\
0\end{array}$ & 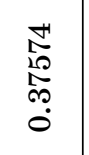 & $\begin{array}{l}\tilde{\omega} \\
0 \\
0 \\
10 \\
0 \\
0\end{array}$ & 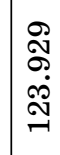 \\
\hline & $\stackrel{2}{1}$ & 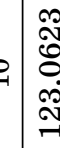 & 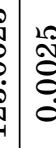 & 采 & 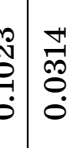 & & 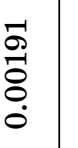 & 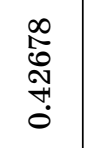 & $\begin{array}{l}10 \\
10 \\
0 \\
0 \\
0 \\
0\end{array}$ & 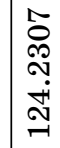 \\
\hline & & N & 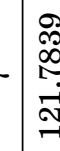 & $\begin{array}{l}\infty \\
0 \\
0\end{array}$ & $\mid \begin{array}{l}\infty \\
\infty \\
\infty \\
0 \\
0\end{array}$ & 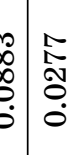 & & \begin{tabular}{l}
\multicolumn{6}{c}{} \\
$\vdots$ \\
$\vdots$ \\
0 \\
0
\end{tabular} & 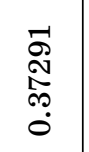 & 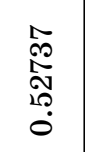 & 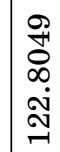 \\
\hline & & مـ & 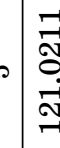 & 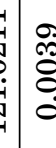 & $\begin{array}{l}0 \\
0 \\
\infty \\
0 \\
0\end{array}$ & 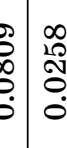 & & $\begin{array}{l}\frac{10}{20} \\
\stackrel{2}{0} \\
0 \\
0 \\
0\end{array}$ & 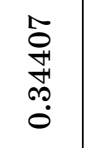 & 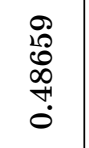 & 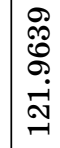 \\
\hline & & -1 & 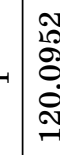 & 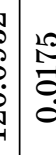 & 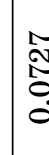 & 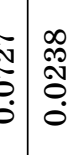 & & 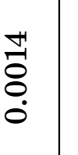 & 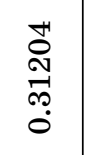 & \begin{tabular}{l} 
I \\
\multirow{J}{*}{} \\
$\stackrel{0}{0}$
\end{tabular} & 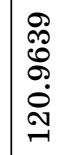 \\
\hline \multicolumn{3}{|c|}{ 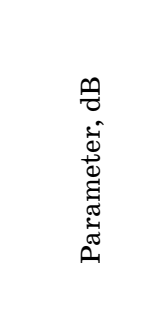 } & 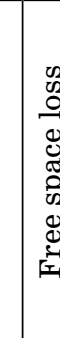 & $\begin{array}{l}0 \\
0 \\
0 \\
0 \\
0 \\
0 \\
0 \\
0\end{array}$ & 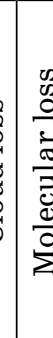 & 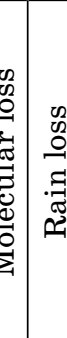 & & 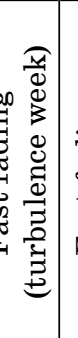 & 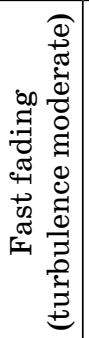 & 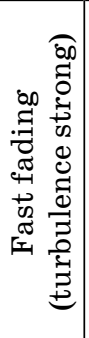 & 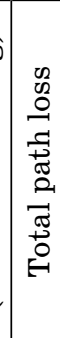 \\
\hline
\end{tabular}

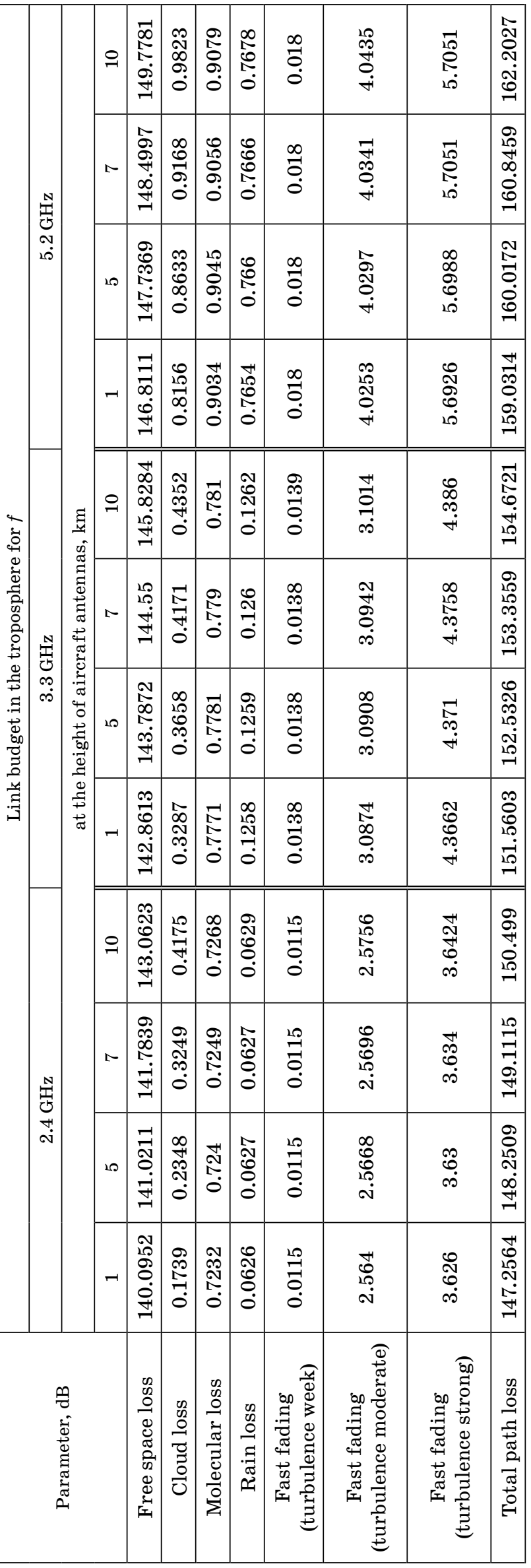



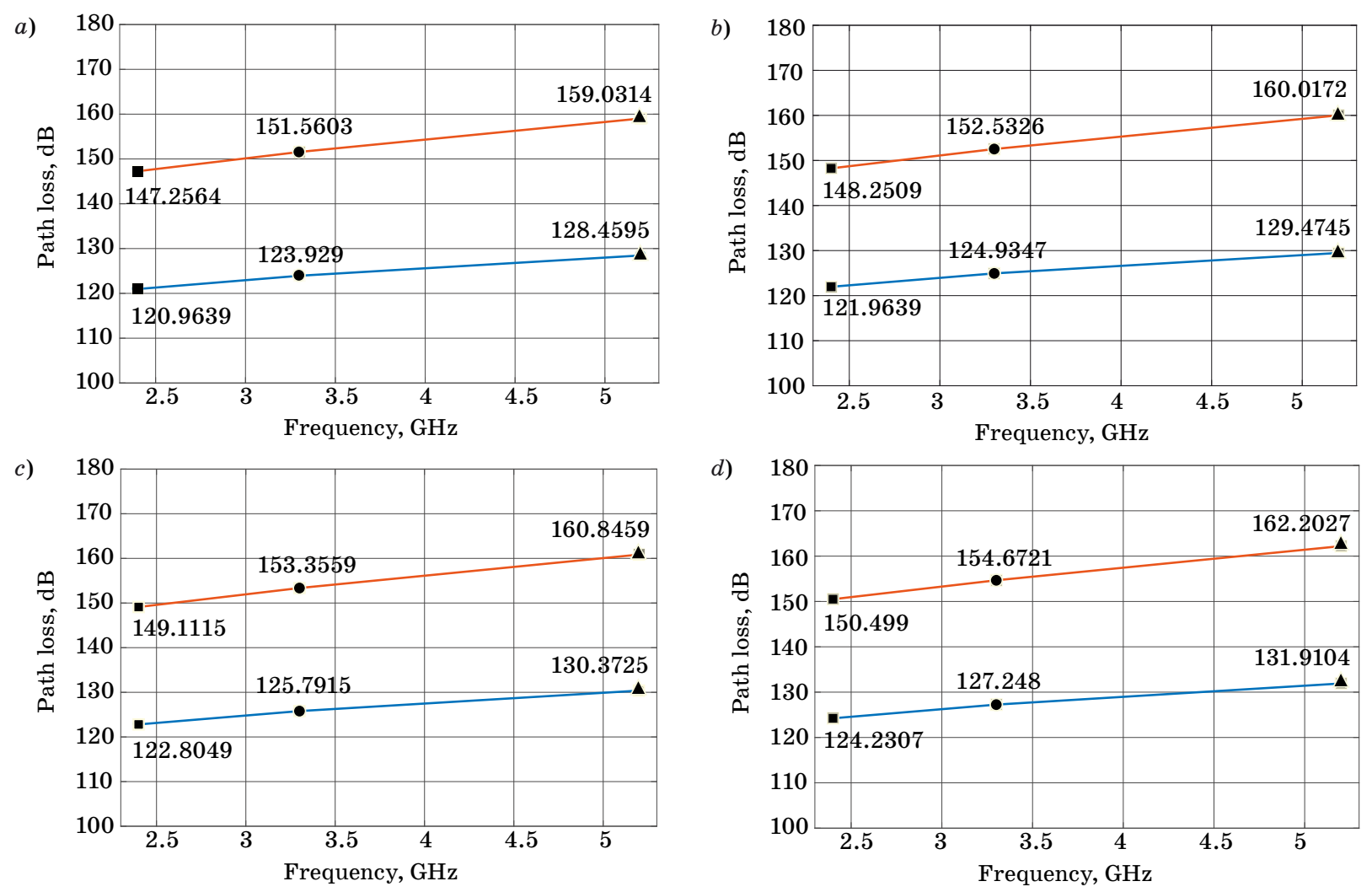

$$
L=10 \mathrm{~km}
$$

$L=100 \mathrm{~km}$

Frequency:

- $-2.4 \mathrm{GHz} \bullet-3.3 \mathrm{GHz} \quad \triangle-5.2 \mathrm{GHz}$

Fig. 12. Total path loss versus frequency for several ranges between the antennas: $a-h=1 \mathrm{~km} ; b-h=5 \mathrm{~km} ; c-h=7 \mathrm{~km} ; d-$ $h=10 \mathrm{~km}$

$$
L_{t o t a l}=\bar{L}+L_{S F}+L_{F F}+\frac{S}{N_{0}}-G_{T}-G_{R}
$$

where $L_{S F}-$ slow fading loss due to diffraction of clouds; $L_{F F}$ - fast fading loss due to effects of turbulence caused by scattering; $\frac{S}{N_{0}}-$ SNR of the Gaussian noise channel; $\bar{L}$ is the average path loss and is equal to the sum of free space attenuation and NLOS condition attenuation, that is

$$
\bar{L}=L_{F S}+L_{N L O S} .
$$

Here $L_{F S}$ - free space path loss; $L_{N L O S}$ - attenuation of hydrometeors such as rain, snow and clouds.

As examples on how to design link budget for atmospheric communication links, we will build our link budget for aircraft height of $1,5,7$ and $10 \mathrm{~km}$, for three frequencies, $f=(2.4,3.3,5.2) \mathrm{GHz}$, corresponding to what is usually used in $4^{\text {th }}$ generation Wi-Fi Technology. In the Tables 1, 2 we will conclude all the losses from hydrometeors, turbulence and free space. The gains of the transmission antenna and the aircraft antenna [dB] will be described as $G_{1}$ and $G_{2}, L$ is the horizontal distance.
In Figs. 12, $a-d$ we examine the link budget for aircraft height antenna of $1,5,7$ and $10 \mathrm{~km}$ for distance $L$ equal to 10 and $100 \mathrm{~km}$.

As follows from Fig. 12, the computations carried out for the specific case correspond with the information presented by in Tables 1, 2. For aircraft height antenna of $5 \mathrm{~km}$ for distance $L=10 \mathrm{~km}$, the path loss exceeds $121.9639,124.9347$ and $129.4745 \mathrm{~dB}$ for frequencies of $2.4,3.3$ and $5.2 \mathrm{GHz}$ respectively.

\section{Effects of turbulence on signal data passing atmospheric communication links}

\section{Characteristics of information signal data in atmospheric communication links}

According to the classical approach, the capacity of the channel with Additive White Gaussian Noise (AWGN) of bandwidth $B_{w}$ is based on the Shannon Hartley formula, which defines the relationship between the maximum data rate via any channel, called the capacity, the bandwidth $B_{w}[\mathrm{~Hz}]$, and the signal-to-noise ratio $\left(\mathrm{SNR} \equiv N_{a d d}\right)$ (see also $\left.[4,5]\right)$ :

$$
C=B_{w} \log _{2}\left[1+\frac{S}{N_{0} B_{w}}\right]
$$


where in our notations, the power of additive noise in the AWGN channel is $N_{a d d}=N_{0} B_{w}$, whereas $S$ is the signal power, and $N_{0}$ is the signal power spectrum, W/Hz.

According to [3-5], SNR equals the ratio between the signal power measured at the input of the receiver, $P_{R}$, and its inner white noise $N_{R}$ :

$$
S N R=10 \log _{10}\left(\frac{P_{R}}{N_{R}}\right)=P_{R}-N_{R}[\mathrm{~dB}] .
$$

Usually, in radio and optical communication, another characteristic, called the spectral efficiency, is utilized:

$$
\tilde{C}=\frac{C}{B_{w}}=\log _{2}\left[1+\frac{S}{N_{0} B_{w}}\right]
$$

Based on the second approach (called the approximate $[4,5]$, accounting for the fading phenomena, flat or multi-selective, we can now introduce in (61) the multiplicative noise by introducing the Ricean $K$-factor of fading, defined above, as the ratio of the coherent and multipath (incoherent) components of signal intensity, that is, $K=I_{c o} / I_{i n c}$, or following special definitions made in [4-6], $K=S / N_{\text {mult }}$. Using these notations, we finally get the capacity as a function of the $K$-factor and the signal to additive noise ratio $\left(\mathrm{SNR}_{a d d}\right)$ :

$$
\begin{aligned}
C= & B_{w} \log _{2}\left(1+\left(S N R_{a d d}^{-1}+K^{-1}\right)^{-1}\right)= \\
= & B_{w} \log _{2}\left(1+\frac{K \cdot S N R_{a d d}}{K+S N R_{a d d}}\right) .
\end{aligned}
$$

Consequently, it is easy to obtain from (62) the spectral efficiency of the channel with fading as a source of multiplicative noise:

$$
\tilde{C}=\frac{C}{B_{w}}=\log _{2}\left(1+\frac{K \cdot S N R_{a d d}}{K+S N R_{a d d}}\right),
$$

where the bandwidth $B_{w}$ changes according to the system under investigation. In a comparison, made in $[4,6]$, between the two approaches, classical and approximate, it was shown that formulas (61) with $N_{a d d}=N_{0} B_{w}$ and (63), are the same description of the channel/system capacity, when the $K$-factor is larger than $\mathrm{SNR}_{a d d}$.

Finally, we can relate the strength of the scintillation introduced above (called the scintillation index), with the $K$-factor of fading. In expression (44), we presented this characteristic, following [4-6], for zero-mean random process. For the convenience of understanding the subject, we present this relation again:

$$
\left\langle\sigma_{I}^{2}\right\rangle=\frac{\left\langle[I-\langle I\rangle]^{2}\right\rangle}{\langle I\rangle^{2}}=\frac{I_{\text {inc }}^{2}}{I_{c o}^{2}} \equiv K^{-2} .
$$

Dependence of $K$-factor of fading versus the signal intensity scintillation $\sigma_{I}^{2}$, was presented in Fig. 10 (see part 1) based on computations made in (44). The range $\left\langle\sigma_{I}^{2}\right\rangle$ of the scintillation index variations, from 0.2 to $\mathbf{0 . 8}$, was obtained from numerous experiments, where relations between this parameter and the refractivity of the turbulence in the irregular atmosphere were taken into account (see also Fig. 7-9). Thus, from experiments described there, it was estimated $\sim C_{n}^{2} \approx 10^{-15} \mathrm{~m}^{-2 / 3}$ and $\sim C_{n}^{2} \approx 10^{-13} \mathrm{~m}^{-2 / 3}$, for a nocturnal and a diurnal atmosphere at the height around 1-2 km, respectively. As follows from Fig. 10, for such values of $\left\langle\sigma_{I}^{2}\right\rangle$, fading parameter $K$ indicates the existence of strong direct visibility between both terminals, the source and the detector, accompanied by weak additional effects of multipath phenomena caused by multiple scattering of signals at the turbulent structures, formed in the disturbed atmospheric regions, observed experimentally $[4,5]$.

Having now information about the $K$-factor, we can predict deviations of the parameters of the data stream (i. e., the signal) in the multipath channels passing through strong turbulence that occurs in the non-homogeneous atmosphere.

Thus, the capacity or spectral efficiency described versus $K$-factor by Eq. (63) and (64), respectively, can easily account for various scenarios occurring in the atmospheric channel and for different conditions of the inner noise of the transmitter as well as the receiver inside the link under consideration. One of the computed examples is presented in Fig. 13, for different additive SNRs and for a "point" receiver (with respect to the range of $1 \mathrm{~km}$ between the terminals).

We took the $K$-parameter much wider, varying in the interval from 0.1 to 500 , that is: to cover the "worst" case when $K<<1$ which is described by Rayleigh law passing the quasi-LOS case; when $K \approx 1$; and finally achieving a situation where $K>>1$ (ideal LOS case in propagation, described by Deltashape Gaussian law). As can be seen, in the strong disturbed irregular atmosphere (with strong turbulence), when $1<K<10$, the spectral efficiency is around (0.7-1.1) for SNR = $1 \mathrm{~dB}$; around 0.7-1.7 for $\mathrm{SNR}=5 \mathrm{~dB}$; and around 0.95-2.55 for $\mathrm{SNR}=10 \mathrm{~dB}$.

Now, since the optical signal can be considered as a carrier of digital information, as a set of bits, effects of multipath fading in any wireless communication channel leads to errors in bits character- 


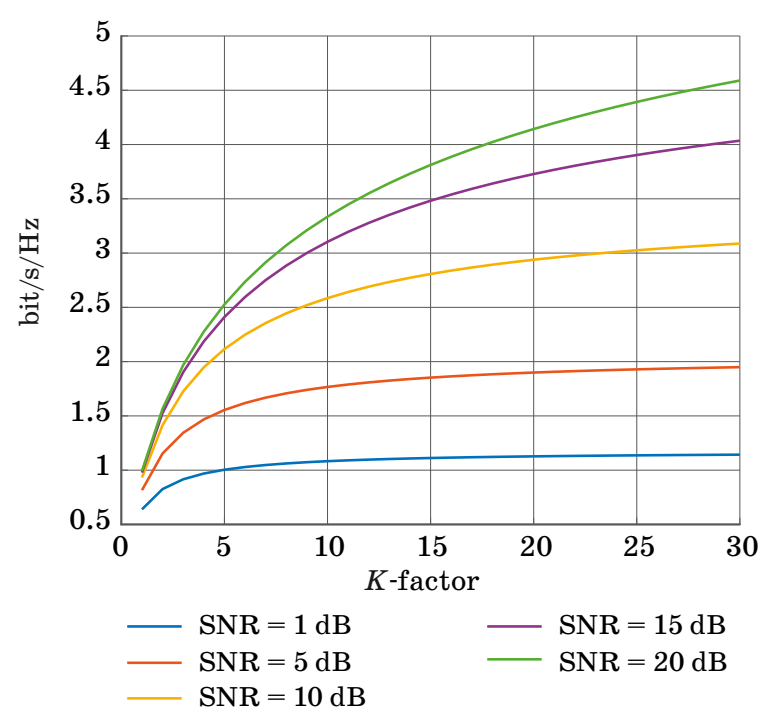

Fig. 13. Spectral efficiency vs. $K$-factor for point receiver

ized by the special parameter defined as BER. Thus, using the Rayleigh distribution for worst cases of strong fading, we can determine the probability of bit error occurring in the multipath channel by the following formula [3-5]:

$$
P_{r}(e)=\frac{1}{\sigma^{2}} \int_{r_{T}}^{\infty} r e^{-\left[\frac{r^{2}}{2 \sigma_{N}^{2}}\right]} \mathrm{d} r=e^{-\left[\frac{r_{T}^{2}}{2 \sigma_{N}^{2}}\right]},
$$

where $P_{r}(e)$ represents evaluated probability of a bit error; $\sigma_{N}^{2}$ is the intensity of interference at the optical receiver (usually determined as the multiplicative noise [3-6]), $r_{T}$ determines the threshold between detection without multiplicative noise (defined as a "good case" [3-6]), and with multiplicative noise (defined as a "worst case" $[4,5]$ ).

In our investigations, we present BER as a function of the Ricean $K$-factor of fading, following results obtained in $[4,5]$, based on Ricean $P D F$, as more commonly used with respect to Rayleigh $P D F$. Thus, following [3-6] and using a classical formula for BER, according to [3] we finally get

$$
B E R=\frac{1}{2} \int_{0}^{\infty} p(x) \operatorname{erfc}\left(\frac{S N R}{2 \sqrt{2}} x\right) \mathrm{d} x,
$$

where $p(x)$ is the probability density function, which in our case the Ricean one was taken, and $\operatorname{erfc}(\cdot)$ is the well-known error function [3-6]. Using the BER definition (66), where the SNR includes also the multiplicative noise, we finally get for BER the following equation:

$$
B E R\left(K, \frac{S}{N_{a d d}}, \sigma\right)=\frac{1}{2} \int_{0}^{\infty} \frac{x}{\sigma^{2}} e^{-\frac{x^{2}}{2 \sigma^{2}}} e^{-K} \times
$$

$$
\times I_{0}\left(\frac{x}{\sigma} \sqrt{2 K}\right) \operatorname{erfc}\left(\frac{K \frac{S}{N_{a d d}}}{2 \sqrt{2}\left(K+\frac{S}{N_{a d d}}\right)} x\right) \mathrm{d} x .
$$

This is an important formula, which gives the relation between the BER and the additive SNR, the Ricean parameter $K$ describes the multipath fading phenomena occurring within the multipath land-satellite communication link passing the ionosphere, and the probability of BER of the information data stream inside such a channel.

\section{Relations between signal data parameters in atmospheric links}

We can now enter into detailed analysis of the key parameters of the wireless atmospheric channel, radio or optic, and the information data, based on the approximate approach proposed above according to [3-6].

We should emphasize that the proposed approach is based on formulas (40), (41), (62)-(64) and (67). This means that with knowledge of the experimentally obtained refractive index structure parameter, $C_{n}^{2}$, that characterizes strength of atmospheric turbulence, one can estimate the scintillation index $\sigma_{I}^{2}$ based on Rytov's law (41). The later can be evaluated based on the relation between $\sigma_{I}^{2}$ and $K$ by use of the relation (64) between them. Considering these parameters, finally using (62)-(64), (67), the BER can be evaluated for various situations occurring in the land-atmosphere or atmosphere-land wireless channels with fading caused by turbulent structure of the troposphere at altitudes from 1 to $10 \mathrm{~km}$.

Thus, we analyze effects of fading (e. g., the changes of the $K$-parameter) on BER conditions within the turbulent wireless communication link consisting of weak and strong turbulences. As shown in $[6,25,26]$, depending on what kind of turbulence - strong turbulence (with $\left\langle C_{n}^{2}\right\rangle=5 \cdot 10^{-14}$ ) occurring at paths up to 100-200 m, or weak turbulence (with $\left\langle C_{n}^{2}\right\rangle=4 \cdot 10^{-16}$ ), occurring at altitudes of $1-2 \mathrm{~km}$ - the effects of fading become stronger in the first case, and weaker in the second case. In other words, at higher atmospheric altitudes for the horizontal atmospheric channels, where the LOScomponent exceeds the multipath (NLOS) component (i. e., for $K>1$ ), the BER-characteristic becomes negligible and can be ignored as well as other fading characteristics in design of land-atmospheric or pure atmospheric links. This result is clearly illustrated by computations presented in Figs. 14, $a$ and $b$ for various SNR and for scintillation index.

As seen from Figs. 14, strong turbulent atmospheric conditions, defined by $C_{n}^{2} \approx 10^{-13} \mathrm{~m}^{-2 / 3}$ (and 
therefore - by $K<2$ ) result in a relatively great BER. This tendency depends also on increases of SNR inside the wireless system. Thus, for an SNR increase of $15 \mathrm{~dB}$, the BER decreases accordingly. So, strong turbulent conditions play a major role in fading effects caused by turbulence, which fully corresponds with results obtained experimentally and theoretically in [25, 26]. Therefore, these are subjects of particular value for estimation of optical communication parameters, such as BER and SNR and prediction of maximal losses, caused by strong turbulence.
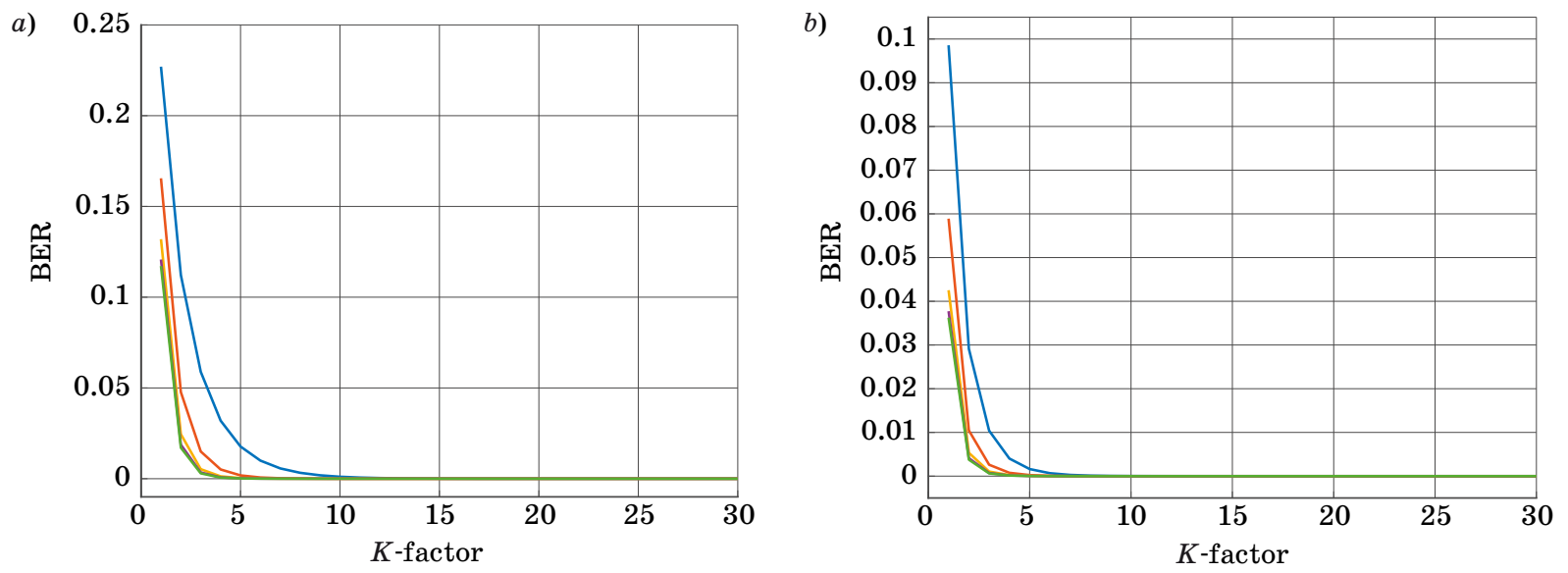

$-\mathrm{SNR}=1 \mathrm{~dB}$

$-\mathrm{SNR}=5 \mathrm{~dB}$

SNR $=10 \mathrm{~dB}$

$-\mathrm{SNR}=15 \mathrm{~dB}$

$\mathrm{SNR}=20 \mathrm{~dB}$

Fig. 14. BER computed by formula (67) vs. $K$-factor for various SNRs: $a-\sigma=2 \mathrm{~dB} ; b-\sigma=5 \mathrm{~dB}$

a)
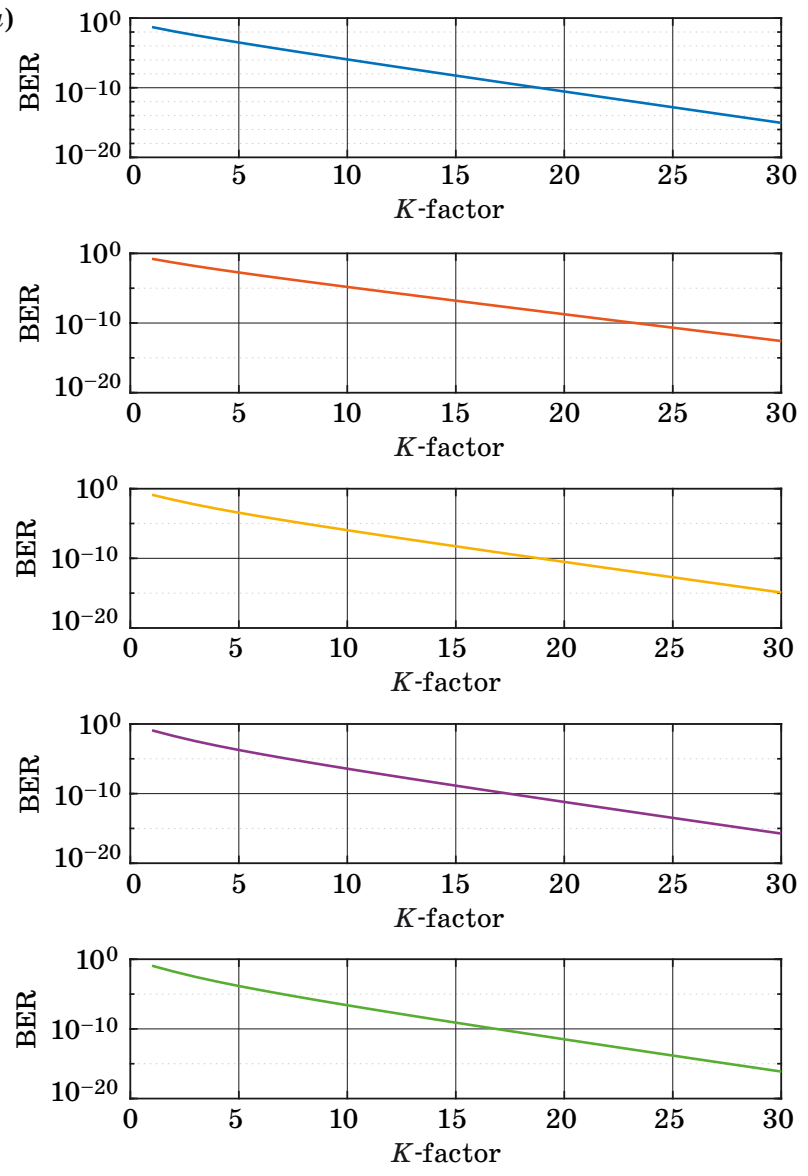

$\mathrm{SNR}=1 \mathrm{~dB}$
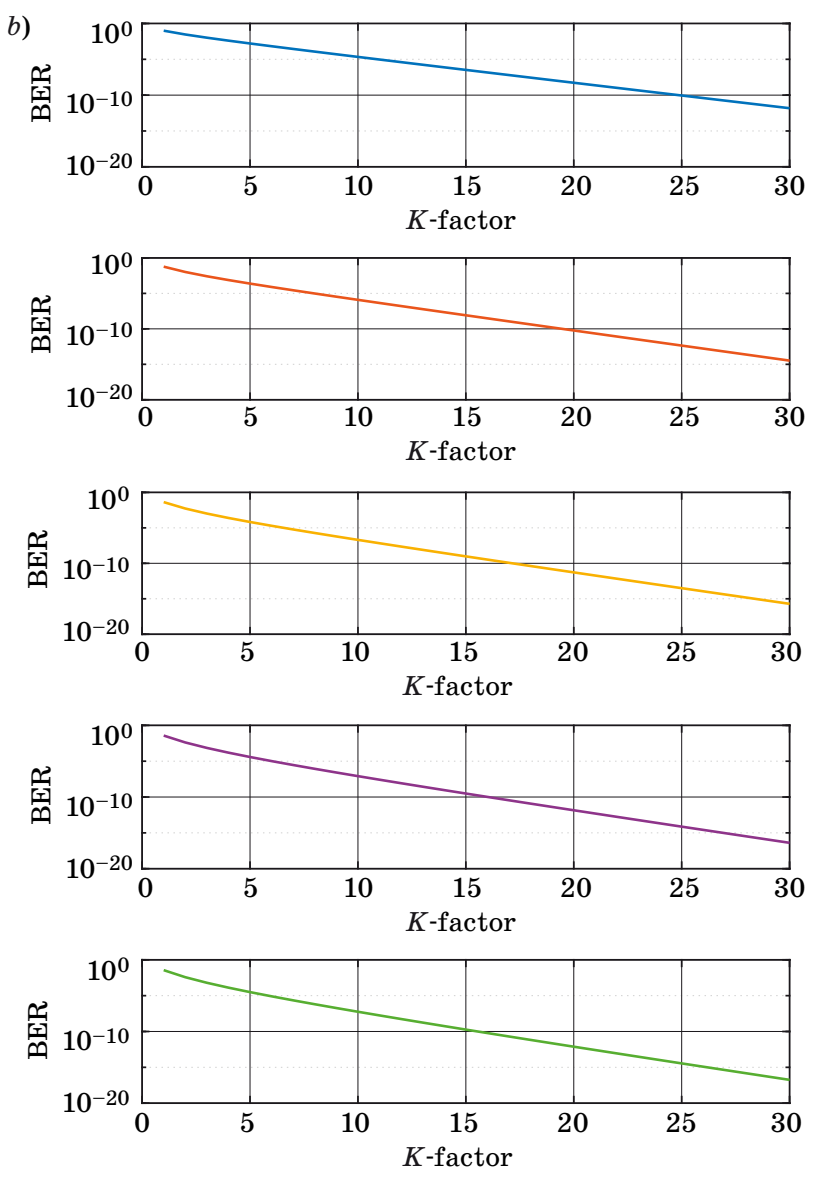

Fig. 15. BER vs. $K$-factor for $\mathrm{SNR}_{a d d}: a-\sigma=2 \mathrm{~dB} ; b-\sigma=5 \mathrm{~dB}$ 
Finally, in [4-6] an optimal algorithm for minimization of the BER of signals was constructed for different situations occurring in wireless atmospheric communication links and for different SNRs occurring in AWGN channels. Thus, taking some measured data, presented in [4-6], we can show here some examples. The results of computations obtained from the relations between $\sigma$ and $K$ are shown in Fig. 15, $a$ and $b$.

As seen from Fig. 15 with an increase of the $K$ parameter; that is, when the LOS component becomes predominant with respect to NLOS multipath components, it is found that BER decreases essentially from $10^{-2}$ for $K \sim 1-2$ to $10^{-6}$ for $K \sim 5-6$ (i. e., for the atmospheric link at altitudes of 100-1000 m filled by turbulent structures [4-6]).

The above results were obtained both for strong and for weak turbulence via measuring of the scintillation index, which allows to estimate deviations of the parameter of fading $K$ : from $K<1-2-$ strong fading, to $K \sim 5-6-$ weak fading, and to $K \sim 10-a b-$ sence of fading. Variations of SNR - from 1 to $20 \mathrm{~dB}$, can only slightly improve a situation with fading.

\section{Summary}

In this work, we investigated tropospheric effects occurring in the corresponding communication channels, relating to the effects of hydrometeors (rain, clouds, etc.) as well as gaseous structures with turbulence, and their main impact on total path loss and fading prediction in the process of total link budget design. We analyzed separately the impact of hydrometeors on attenuation; and turbulence on scattering (e. g. fast fading) of signals with data passing tropospheric wireless communication links.

A link budget was performed for more attractive frequencies used in $\mathrm{Wi}-\mathrm{Fi}$ communication links (from 2.3 to $5.3 \mathrm{GHz}$ ) for different distances between the ground-based subscriber antenna and flying subscriber antenna. Some specific examples were presented for close and far ranges between the terminal antennas at 10 and $100 \mathrm{~km}$.

Using obtained relations between the $K$-factor of fading and the scintillation index, usually applicable in turbulent atmosphere, one can a-priori predict the rate of information data signals, the BER, and the spectral efficiency of each atmospheric channel based on "reaction" of the atmospheric environment and its features on signal data stream passing the atmospheric wireless channel.

Finally, we can conclude that accounting for different impacts of atmospheric features and structures, a designer of wireless atmospheric communication links can more precisely predict the total path loss and, consequently, can design the link budget and arrange the terminal antennas with the prescribed correct amplification, so as to overcome and obey all losses and fading phenomena met in such kinds of links.

\section{References}

1. Zuev V. E., and G. M. Krekov. Optical Methods in the Atmosphere. Leningrad, Gidrometeoizdat Publ., 1986. 256 p. (In Russian).

2. Kopeika N. S. A System Engineering Approach to Imaging, Billingham, WA, SPIE Press, 1998. 704 p.

3. Saunders S. R. Antennas and Propagation for Wireless Communication Systems. John Wiley \& Sons, New York, 2007. 546 p.

4. Blaunstei N., and Ch. Christodoulou. Radio Propagation and Adaptive Antennas for Wireless Communication Links: Terrestrial, Atmospheric and Ionospheric. Wiley InterScience, NJ, 2007. 614 p.

5. Blaunstein N., and Ch. Christodoulou. Radio Propagation and Adaptive Antennas for Wireless Communication Networks: Terrestrial, Atmospheric and Ionospheric. Wiley, NJ, 2014. $704 \mathrm{p}$.

6. Blaunstein N., Arnon Sh., Zilberman A., and Kopeika N. Applied Aspects of Optical Communication and LIDAR. New York, CRC Press, Taylor \&Francis Group, 2010. $262 \mathrm{p}$.

7. Optical Waves and Laser Beams in the Irregular Atmosphere. Ed. by N. Blaunstein, and N. Kopeika. Boca Raton, FL, CRC Press, Taylor\&Frances Group, 2018. 334 p.
8. d'Almeida G. A., Koepke P., Shettle E. P. Atmospheric Aerosols. Global Climatology and Radiative Charac teristics. Deepak Publishing, Hampton, 1991. 561 p.

9. Deirmendjian D. Electromagnetic Scattering on Spherical Polydispersions. American Elsevier, New York, 1969. 318 p.

10. Seinfeld J. H. Atmospheric Chemistry and Physics of Air Pollution. John Wiley \& Sons, New York, 1986. 768 p.

11. Attenuation due to clouds and fog. ITU-R Recommendation International Telecommunication Union, 1992, pp. 840-842.

12. Chou M. D. Parametrizations for cloud overlapping and shortwave single scattering properties for use in general circulation and cloud ensemble models. J. Climate, 1998, vol. 11, pp. 202-214.

13. Wei Zhang. Scattering of radiowaves by a melting layer of precipitation in backward and forward directions. IEEE Transactions on Antennas and Propagation, 1994, vol. 42, no. 3, pp. 347-356.

14. Crane R. K. Prediction of attenuation by rain. IEEE Trans. Commun, 1980, vol. 28, pp. 1717-1733.

15. Lin D. P., and Chen H. Y. An empirical formula for the prediction of rain attenuation in frequency range 0.6-100 GHz. IEEE Trans. on Antennas Propagat, 2002 , vol. 50 , pp. 545-551. 
16. ITU-R Recommendation International Telecommunication Union "Specific attenuation model for rain for use in prediction methods”, Geneva, 1992, p. 838.

17. Kooi P.-S., Leong M.-S., Li L.-W., et al. Microwave attenuation by realistically distorted raindrops: Part II - predictions. IEEE Transactions on Antennas and Propagation, 1995, vol. 43, pp. 821-828.

18. Jaenicke R. Aerosol Physics and Chemistry. In: Physical Chemical Properties of the Air, Geophysics and Space Research, vol. 4 (b). Ed. G. Fisher. Berlin, Springer-Verlag, 1988.

19. Rosen J. M., and Hofmann D. J. Optical modeling of stratospheric aerosols: present status. Appl. Opt., 1986, vol. 25(3), pp. 410-419.

20.ITU-R International Telecommunication Union, ITU-R Recommendation "Attenuation by atmospheric gases”, 1997, pp. 676-683.

21. ITU-R Recommendation International Telecommunication Union "Propagation data and prediction meth- ods required for the design of terrestrial line-of-sight systems", 1997, pp. 530-537.

22.ITU-R Recommendation International Telecommunication Union "Characteristics of precipitation for propagating modeling”, 1992, p. 837.

23. Ishimaru A. Wave Propagation and Scattering in Random Media. Academic Press, New York, 1978. 272 p.

24. Andrews L. C., and Phillips R. L. Laser Beam Propa gation through Random Media. 2nd Ed. SPIE Press, Bellingham, WA, USA, 2005. 808 p.

25. Bendersky S., Kopeika N., and Blaustein N. Prediction and modeling of line-of-sight bending near ground level for long atmospheric paths. Proc. of SPIE Int. Conf., San Dieg, August 3-8, 2004, pp. 512-522.

26. Bendersky S., Kopeika N., and Blaunstein N. Atmospheric optical turbulence over land in middle-east coastal environments: prediction, modeling and measurements. J.Applied Optics, 2004, vol. 43, pp. 4070-4079.

УДК 621.371

doi:10.31799/1684-8853-2020-1-54-62

Анализ полных потерь сигнала и пропускной способности информации в атмосферных беспроводных каналах связи. Часть 2

И. Джувилер ${ }^{\mathrm{a}}, \mathrm{PhD}$, старший преподаватель, orcid.org/ 0000-0002-0669-7828

И. Бронфман ${ }^{\text {, }, ~ а с с и с т е н т, ~ o r c i d . o r g / ~ 0000-0001-6195-069 X ~}$

Н. Блаунштейн ${ }^{\sigma}$, доктор физ.-мат. наук, профессор, orcid.org/ 0000-0003-2945-9379, nathan.blaunstein@hotmail.com атехнический колледж им. Сами Шамуна, ул. Жаботинского, 84, Ашдод, 77245, Израиль

${ }^{6}$ Негевский университет им. Бен-Гуриона, П.О.Б. 653, Бен-Гуриона ул., 1, Беэр-Шева, 74105, Израиль

Введение: анализ полного затухания сигнала основан на прогнозе полных потерь, имеющих место в атмосферных каналах связи, учитывающем эффекты затухания и рассеяния на газообразующих структурах, поглощения и потерь от гидрометеоров (дождя, снега, облаков), быстрого фединга турбулентных структур на радио- и оптические сигналы, распространяющиеся в атмосферных каналах с федингом. Цель исследования: разработка новой методологии определения и оценки эффектов затухания, поглощения, рассеяния, и фединга радио- и оптических сигналов, распространяющихся в атмосферных каналах в различных метеорологических условиях. Результаты: проанализирован вклад газообразующих структур, гидрометеоров и турбулентных структур в полные потери сигнала для дизайна бюджета канала и в деградацию параметров информационного потока данных, таких как пропускная способность, спектральная эффективность и скорость потерь в битах, которые в итоге приводят к потере информационных сигналов, распространяющихся в каналах связи с быстрым федингом, и к уменьшению качества сервиса. Найден оптимальный алгоритм прогноза полных потерь для различных метеорологических условий, имеющих место в реальной атмосфере на различных высотах, и для различных частот излучаемых сигналов. Предложен метод оценки параметров потока информации, таких как пропускная способность, или емкость, спектральная эффективность и скорость потерь в битах. Данный метод учитывает эффекты вклада атмосферной турбулентности в быстрый фединг, который разрушает информацию, проходящую через каналы такого типа. Все практические тесты проиллюстрированы с использованием программирования на МАТLАВ. Предложена новая методика определения и оценки пропускной способности, спектральной эффективности и потерь в энергии и в потоке информационных битов при различных сценариях прохождения информационных сигналов, радио и оптических, через атмосферные беспроводные каналы связи с федингом, вызванным различными метеорологическими условиями. Практическая значимость: полученные результаты позволяют добиться улучшенной точности прогноза и повысить качество сервиса в атмосферных каналах связи.

Ключевые слова - быстрый фединг, газообразующие структуры, гидрометеоры, дождь, емкость (пропускная способность), затухание, индекс сцинтилляции, $K$-фактор Райса, облака, поглощение, скорость битовой ошибки, снег, спектральная эффективность, турбулентность.

Для цитирования: Juwiler I., Bronfman I., Blaunstein N. Analysis of total signal decay and capacity of information data in wireless atmospheric communication links. Part 2. Информационно-управляющие систелы, 2020, № 1, с. 54-62. doi:10.31799/1684-88532020-1-54-62

For citation: Juwiler I., Bronfman I., Blaunstein N. Analysis of total signal decay and capacity of information data in wireless atmospheric communication links. Part 2. Informatsionno-upravliaiushchie sistemy [Information and Control Systems], 2020, no. 1, pp. 54-62. doi:10.31799/1684-8853-2020-1-54-62 